\title{
AIR FLOW ANALYSIS FOR ELECTRICAL MOTOR'S COOLING SYSTEM WITH AUTODESK SIMULATION CFD 2013 PROGRAM
}

\author{
Jerzy MADEJ*, Bartłomiej BĘDKOWSKI*
}

${ }^{*}$ Faculty of Mechanical Engineering and Computer Science, University of Bielsko-Biala, ul. Willowa 2, 43-309 Bielsko-Biała, Poland "Institute Research \& Development Centre of Electrical Machines "KOMEL", 188 Roździeńskiego Ave., 40-203 Katowice, Poland

\author{
juma@ath.bielsko.pl, b.bedkowski@komel.katowice.pl
}

\begin{abstract}
In the article the analysis of airflow through electrical motor was conducted and optimal design solution was chosen in order to increase cooling efficiency. Numerical simulations allow to determine the areas of temperature occurrence which may have destructive influence on electrical motor parts and on its safe operation. The numerical calculations of airflow was carried out for two different types of fans as well as for two different housings. An analysis of the construction was carried out by CFD method using Autodesk Simulation CFD 2013. Community results of the analysis, we can conclude that the better solution for machines with fixed direction of rotation is to use instead of the radial the axial fan. For axial fan the motor temperature in the same condition was lower by about $5^{\circ} \mathrm{C}$.
\end{abstract}

Key words: Gas And Thermal Flow Analysis, Electrical Motors, Cooling Systems, CFD

\section{INTRODUCTION}

The modern design studies demand higher efficiency and miniaturization of electrical motors at low production costs. Mechanical and electrical losses and efficiency of these types of devices are directly connected with operation temperature, and these values decide about technical and economical indexes of electrical machines.

The use of elements sensitive to high temperature such as permanent magnets, encoders, seal or bearings as well as growing variety of operating conditions are the main causes for giving more attention to the phenomenon of flow and heat transfer and implementing such constructions, which will ensure optimal machine operation. Hence, it is important to find the nature of the flow phenomena that occurs in mechanical structures.

Making effective analyzes of heat transfer, gases and liquids flows around the device, and inside of it are now possible thanks to the use of specialized computing systems based on CFD algorithms, such analysis of electric machines we can find in the works of other authors (Będkowski and Madej, 2012; Boglietti et al., 2009; Chang et al., 2010; Dorrell et al., 2006; Hongmin, 2009, 2010; Lim et al., 2010; Szczypior and Jakubowski, 2009). The CFD analysis of impellers we can see in the works (Kelly and Gigas, 2003; Murthy et al., 2007). For this type of analysis The Autodesk Simulation CFD deserves attention.

\section{PURPOSE AND SCOPE OF WORK}

The purpose of this study was to calculate the parameters of the airflow, heat transfer and the cooling system efficiency of the electrical motor depending on the type of the fan and the changes made in the housing construction. The motor of the high of $80 \mathrm{~mm}$ and the power of $1 \mathrm{~kW}$, operating at $1500 \mathrm{rpm}$ speed was the object of discussion. The simplified model is shown in Fig. 1.
The view of exploded motor assembly with an indication of the parts' material uses for the calculation is shown in Fig. 2.

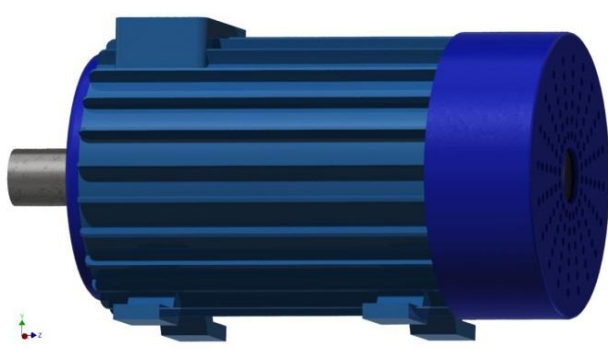

Fig. 1. The model of motor with short fan cover

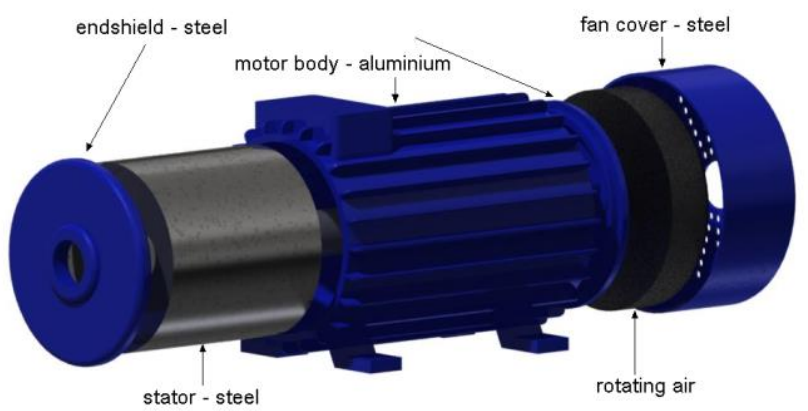

Fig. 2. The view of exploded motor assembly

It was assumed that the initial temperature of the ambient air of the motor is $20^{\circ} \mathrm{C}$, and of the same, constant temperature is the air flowing into the fan case. It was also assumed that the only source of heat energy of $250 \mathrm{~W}$ is the stator body. It includes the losses of iron $\Delta \mathrm{P}_{\mathrm{Fe}}$ and losses in the stator windings $\Delta \mathrm{P}_{\mathrm{Cu}}$ (from passage of current in the winding). The fan and bearings' mechanical losses and electrical losses in the rotor, which for perma- 
nent magnet machines working with these rotational speeds are usually negligible, were omitted.

To assess efficient cooling, the two types of six blades fans (shown in Fig. 3) calculations were performed.

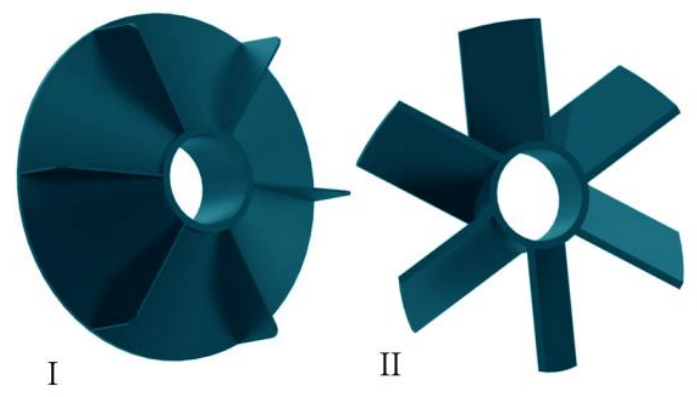

Fig. 3. Types of considered fans

\section{NUMERICAL SIMULATIONS}

The numerical calculations were made with Autodesk Simulation CFD 2013 program which is intended for flow and heat transfer analyzes. In this program, the simulation of the airflow from rotating fan was conducted as a transient analysis. This type of analysis requires time-consuming calculations and high computing power, but it has an important advantage - a continuous recording and presentation of the airflow distribution parameters at any time during study. It is of great importance for the subsequent experimental verification of obtained calculations.

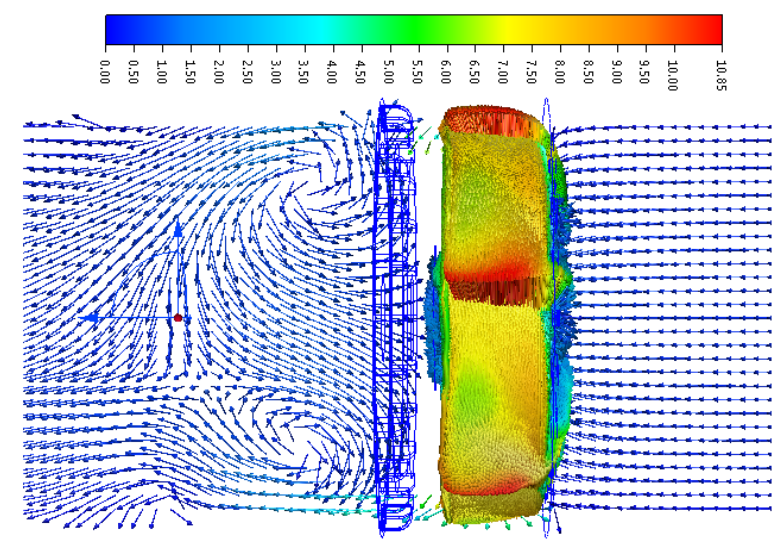

Fig. 4. The airflow view for fan I

Initial simulations revealed that in the complicated discrete model, simultaneous calculations of the airflow and heat transfer are practically impossible because of the problem with solution convergence.

Consequently, repeated attempts made to obtain stable solutions led to developing a two-step methodology for the calculation. In the first stage of the calculation, as a result of a transient analysis, fan volume flow rate parameters were obtained with the assumption about the flow resistance of the electrical motor cooling system.

The obtained results of the airflow for both types of the fans are shown in Fig. 4 and 5. The carried out calculations showed that the $5.5^{*} 10^{6} \mathrm{~mm} 3 / \mathrm{s}$ volume flow rates for first type of the fan and the $6.7^{* 10^{6}} \mathrm{~mm}^{3} / \mathrm{s}$ for the second type of the fan were reached. These values were input data to the calculations carried out in the second phase. Steady State analyzes of cooling and airflow along motor body were included in the second stage.

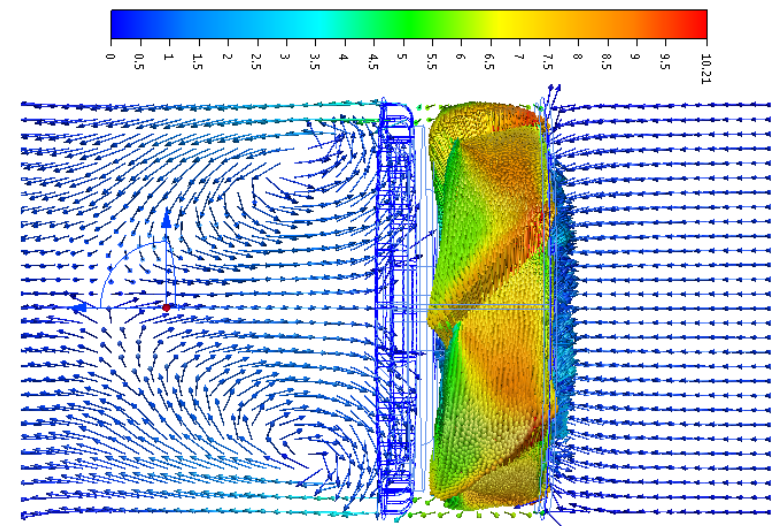

Fig. 5. The airflow view for fan II

\subsection{The typical motor with short fan cover}

As a result of the simulation performed in the second phase for the motor with short fan case (shown in Fig. 1), the airflow and temperature distribution with the use of both types of fans were obtained.

The vertical cross-section view of steady state airflow with velocity vectors along motor body is shown in Fig. 6 .

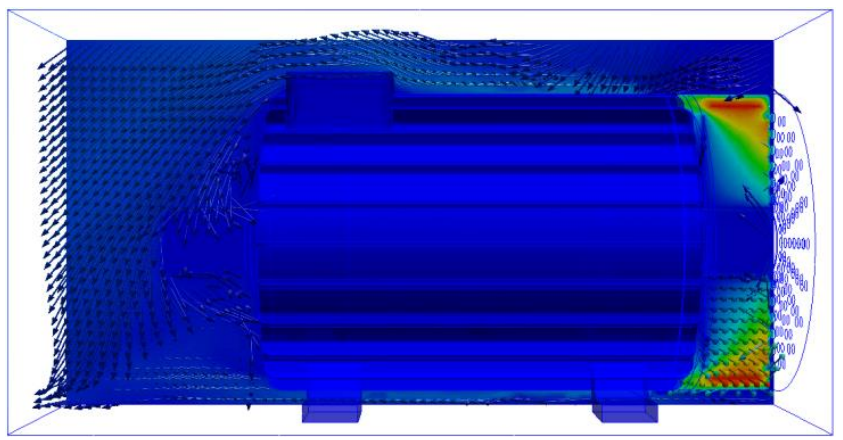

Fig. 6. The airflow with velocity vectors along motor body (vertical cross-section

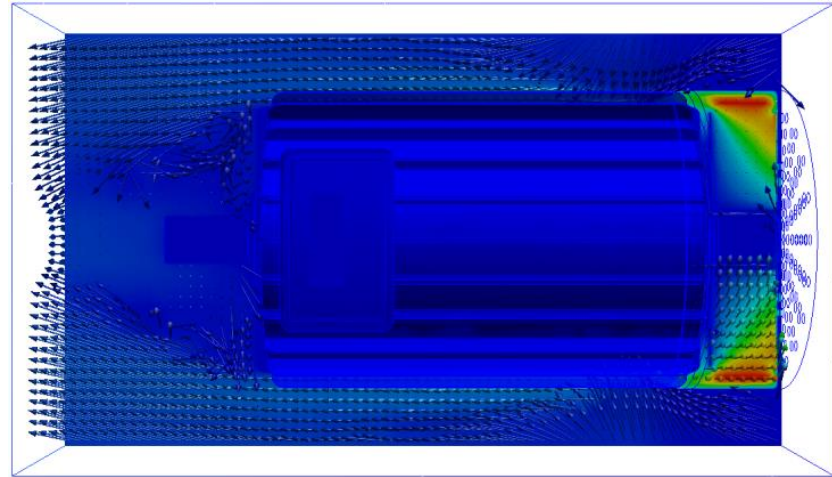

Fig. 7. The airflow with velocity vectors along motor body (horizontal cross-section) 
Fig. 7 shows the airflow with velocity vectors along the motor body in the horizontal cross-section view.

The air flow pattern for both types of fans was the same. Only volume flow rate was different than one assumed for calculations. In accordance to the assumptions previously described for the second stage of the calculation.

While analyzing the obtained results, it can be seen that the cooling airflow at the fan's cover outlet is turbulent and along the body it is of low speed. Much of the airflow dissipates to the sides, which can affect the cooling efficiency.

The steady-state temperature distribution of electric motor for the first type of fan is shown in Fig. 8. The steady-state corresponds to 40 minutes of operation at full power, which was tested by solving a transient problem. The $76.3^{\circ} \mathrm{C}$ maximum temperature inside the motor was reached.

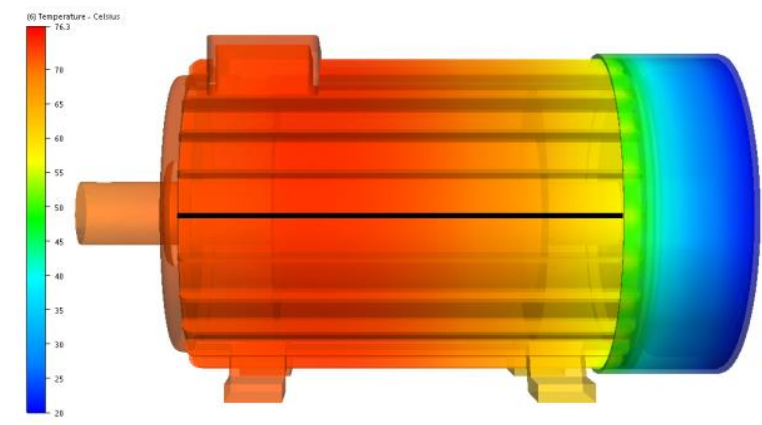

Fig. 8. The temperature profile of motor side

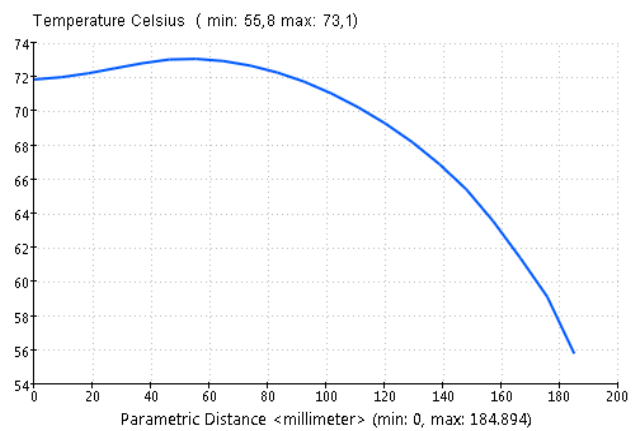

Fig. 9. The temperature diagram along cooling fin edge

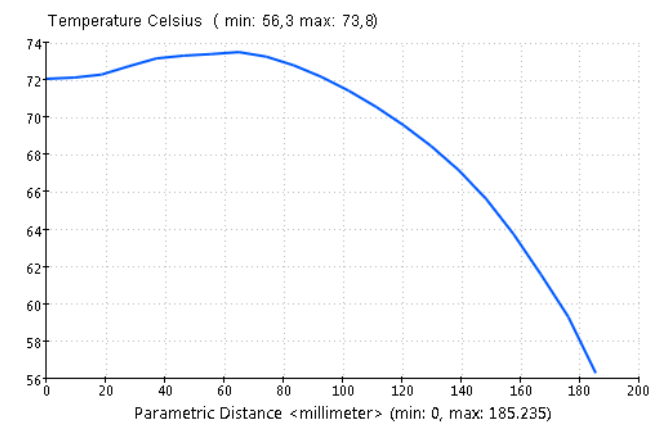

Fig. 10. The temperature diagram along cooling fin edge on the upper motor side

Fig. 9 shows the distribution of temperature registered along cooling fin edge highlighted in Fig. 8 in black. The maximum temperature reached at the fin edge was $73.1^{\circ} \mathrm{C}$, the minimum temperature was $55.8^{\circ} \mathrm{C}$.

Fig. 10 shows the analogous distribution of temperature along cooling fin edge on the upper motor side. Temperature difference was small. The maximum temperature was $73.8^{\circ} \mathrm{C}$ and the minimum temperature was $56.3^{\circ} \mathrm{C}$.

For the second type of fan maximum temperature reached inside the motor was lower and reached $71.2^{\circ} \mathrm{C}$. The maximum temperature reached at the fin edge (shown in Fig. 8) was $67.9^{\circ} \mathrm{C}$, the minimum $51.3^{\circ} \mathrm{C}$ and in the upper part of the motor it respectively reached $68.2^{\circ} \mathrm{C}$ and $52.1^{\circ} \mathrm{C}$ (see tab.1).

Tab. 1. Compare temperatures for both fan types

\begin{tabular}{|c|c|c|}
\hline & Fan I & Fan II \\
\hline $\mathrm{T}_{\max }\left[{ }^{\circ} \mathrm{C}\right]$ for motor & 76.3 & 71.2 \\
\hline $\begin{array}{c}\mathrm{T}_{\max } / \mathrm{T}_{\min }\left[{ }^{\circ} \mathrm{C}\right] \text { on radiator of the } \\
\text { lateral motor side }\end{array}$ & $73.1 / 55.8$ & $67.9 / 51.3$ \\
\hline $\begin{array}{c}\mathrm{T}_{\max } / \mathrm{T}_{\min }\left[{ }^{\circ} \mathrm{C}\right] \text { on radiator of the } \\
\text { upper motor side }\end{array}$ & $73.8 / 65.3$ & $68.2 / 52.1$ \\
\hline
\end{tabular}

This data shows that the efficiency of the motor cooling fan depends on its geometry which seems to be a fairly obvious conclusion.

\subsection{The motor with additional housing}

Motor cooling efficiency depends on the fan built in it. It seems that lower motor temperature can be reached by the various design modifications. By directional airflow stream we can attain and increase the airflow speed along the motor body without changing the rotational parameters of the fan. The lengthening of the front of the motor body additional housing (Fig. 11) can be one of such proposals.

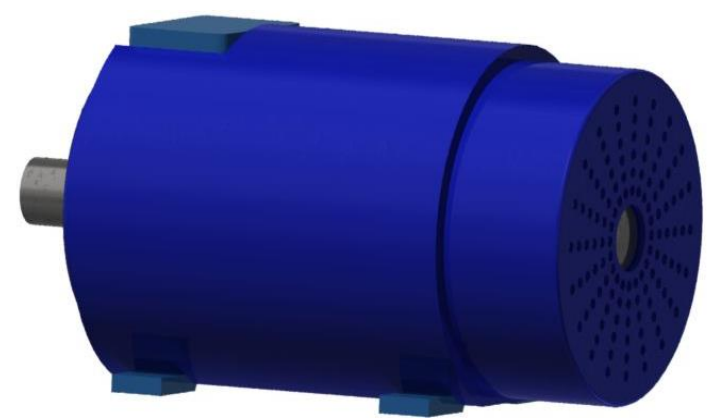

Fig. 11. The model of motor with additional housing

This modification compared to previous solutions caused a change in the structural character of the cooling airflow. The airflow character for motor with additional housing is shown In Fig. 12-13.

The airflow for the first type of fan caused an increase of the maximum temperature inside the motor. Compared to the previous solution which reached about $10^{\circ} \mathrm{C}\left(84^{\circ} \mathrm{C}\right.$ - cf., Fig. 14) and for the second type of fan $6^{\circ} \mathrm{C}\left(76.9^{\circ} \mathrm{C}\right)$. Which has certainly negative effect on electric motor components.

However, the maximum temperature on the surface of the side of additional housing for the solution with first type of fan was $64.2^{\circ} \mathrm{C}$, which was lower by about $9^{\circ} \mathrm{C}$, and the minimum temperature was higher by $2^{\circ} \mathrm{C}$ as it was $57.9^{\circ} \mathrm{C}$. On the top surface, the average rise of temperature was about $3^{\circ} \mathrm{C}$ (maximum $78.3^{\circ} \mathrm{C}$, minimum $59.0^{\circ} \mathrm{C}$ ). 


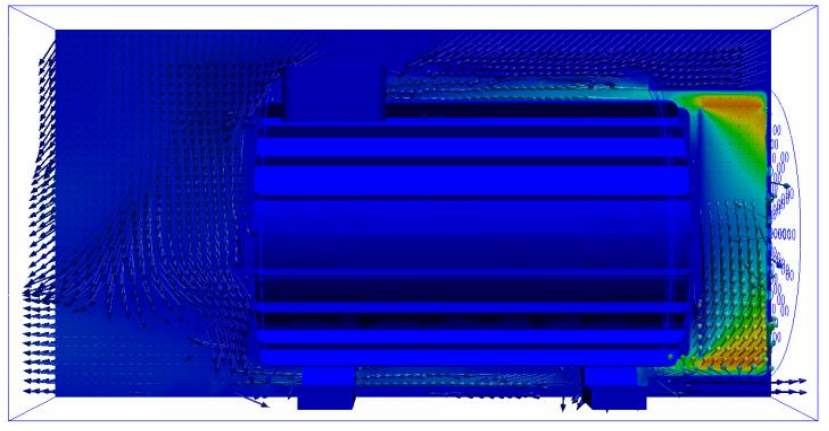

Fig. 12. The airflow with velocity vectors along motor body (vertical cross-section)

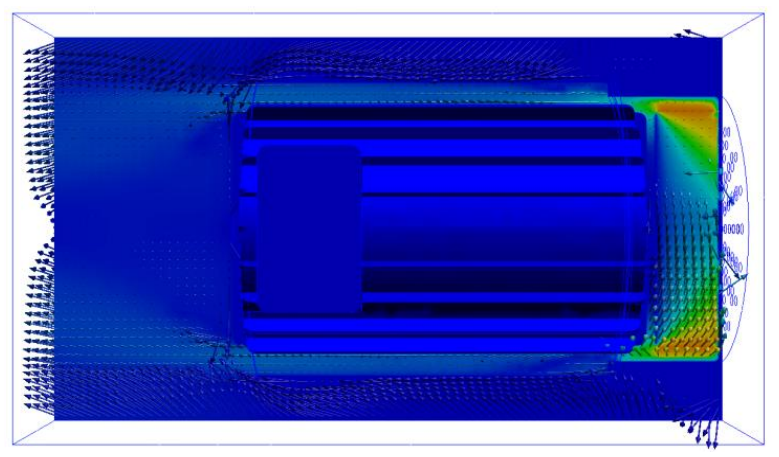

Fig. 13. The airflow with velocity vectors along motor body (horizontal cross-section)

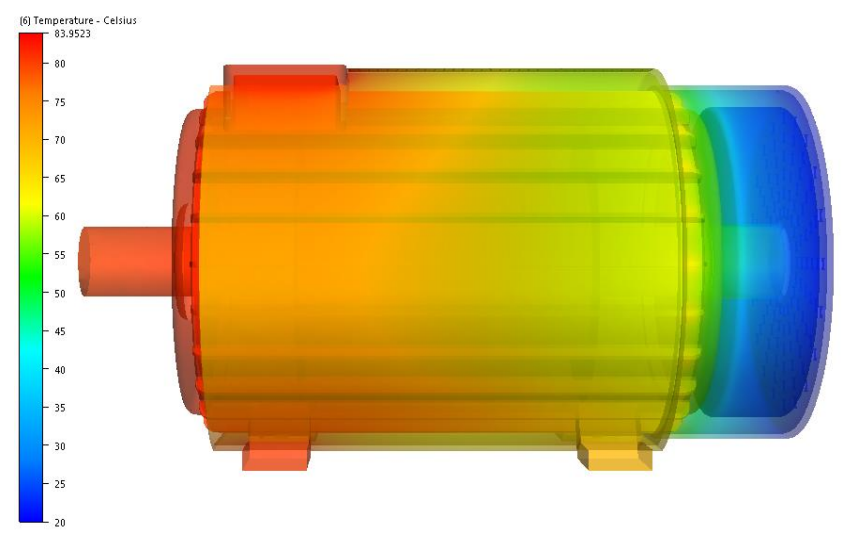

Fig. 14. The temperature profile of motor with additional housing

For solutions with the second type of fan on the side surface of the additional housing the maximum temperature was lower of almost $11^{\circ} \mathrm{C}\left(57.0^{\circ} \mathrm{C}\right)$ and the minimum temperature was the same, and on the top surface the maximum temperature was higher of about $4^{\circ} \mathrm{C}\left(72.0^{\circ} \mathrm{C}\right)$ and the minimum temperature was almost the same (Tab 2).

Tab. 2. Compare temperatures for the two types of housing using fan II

\begin{tabular}{|l|c|c|}
\hline \multicolumn{1}{|c|}{$\mathbf{T}_{\max }\left[{ }^{\circ} \mathrm{C}\right]$ for fan II } & $\begin{array}{c}\text { Motor with } \\
\text { clasical } \\
\text { housing }\end{array}$ & $\begin{array}{c}\text { Motor with } \\
\text { additional } \\
\text { housing }\end{array}$ \\
\hline On surface of the lateral housing side & 71.2 & 76.9 \\
\hline On surface of the upper housing side & & 57.0 \\
\hline On radiator of the lateral side & 67.9 & 72.0 \\
\hline On radiator of the upper side & 68.2 & \\
\hline
\end{tabular}

It seems likely that better results in terms of cooling can be achieved by modeling the cover in the form of a cone extended towards the front of the motor.

Obtaining a lower temperature on the housing can have a positive impact on the safety of the device usage.

\section{SUMMARY}

Numerical simulations confirm that the cooling efficiency of the electrical motors depends on the type of the cooling fan used. The first type of fan which is widely used in electric motors is not optimal in cooling system and it is sufficient only for a temporary work with full power or permanent work with a low load. The second type of the fans considered is a more effective solution, as it is much lighter and easier to build. It seems that, regardless of the fan design, to make proper cooling system for permanent work machine, we must use the rotational airflow from rotating fan.

The results of the analysis of the airflow and temperature parameters for the various constructions may be useful for the diagnosis and the design of cooling systems of electrical motors. What is more, thanks to the results of numerical analyzes, the actual state of the machine can be better known. That allows to predict optimal machine's operation in various conditions. The results of numerical analysis will be soon subjected to rigorous experimental verification.

\section{REFERENCES}

1. Będkowski B., Madej J. (2012), The potential of 3D FEM and CFD methods for cooling systems analysis of electrical machines - the premises, Zeszyty Problemowe Maszyny Elektryczne, BOBRME Komel, No. 3, 139-143.

2. Boglietti A., Cavagnino A., Staton D., Shanel M., Mueller M., Mejuto C. (2009), Evolution and Modern Approaches for Thermal Analysis of Electrical Machine, IEEE Trans. Ind. Electron., Vol. 56, 3, 871-882.

3. Chang C.C., Kuo Y.F., Wang J.C., Chen S.L.(2010), Air cooling for a large-scale motor, Applied Thermal Engineering, Vol. 30, 11-12, 1360-1368.

4. Dorrell D. G., Staton D. A., Hahout J., Hawkins D., McGilp M. I. (2006), Linked Electromagnetic and Thermal Modelling of a Permanent Magnet Motor, PEMD Servo Motor Thermal Analysis.

5. Hongmin Li. (2009), Flow driven by a stamped metal cooling fan Numerical model and validation, Experimental Thermal and Fluid Science, Vol. 33, 4, 683-694.

6. Hongmin Li. (2010), Cooling of a permanent magnet electric motor with a centrifugal impeller, International Journal of Heat and Mass Transfer, Vol. 53, 4, 31, 797-810.

7. Kelly W., Gigas B. (2003), Using CFD to predict the behavior of power law fluids near axial-flow impellers operating in the transitional flow regime, Chemical Engineering Science, Vol. 58, 10, 2141-2152.

8. Murthy B.N., Deshmukh N.A., Patwardhan A.W., Joshi J.B. (2007), Hollow self-inducing impellers: Flow visualization and CFD simulation, Chemical Engineering Science, Vol. 62, 14, 3839-3848.

9. Lim C.H., Airoldi G., Bumby J.R., Dominy R.G., Ingram G.I., Mahkamov K., Brown N.L., Mebarki A., Shanel M. (2010), Experimental and CFD investigation of a lumped parameter thermal model of a single-sided, slotted axial flux generator, International Journal of Thermal Sciences, Vol. 49, 9, 1732-1741.

10. Szczypior J., Jakubowski R. (2009), Calculation of heat storage in the coreless machine with permanent magnet with direct cooling, Zeszyty Problemowe Maszyny Elektryczne, BOBRME Komel, No. 83, 59-66. 